\title{
Assessment of chemical exposures on ECC containing stone slurry powder
}

\author{
Maninder Singh, Babita Saini* and H.D.Chalak \\ Department of Civil Engineering, National Institute of Technology, Kurukshetra, Haryana, India. \\ *Corresponding Author: bsaini@nitkkr.ac.in
}

Submitted :26/04/2020

Revised :23/05/2021

Accepted :26/06/2021

\begin{abstract}
Generation of solid waste materials from various industrial sources is becoming a challenging issue for safe disposal. Durability performance of hydraulic structures under environmental loadings (aggressive substances) is also a concerning issue. The present paper investigated the durability performance of engineered cementitious composite (ECC) mortar containing stone slurry powder (SSP). SSP was used as partial subrogation of micro silica sand (MSS) and fine sand (FS) by $25 \%$ and $50 \%$ for each type of sand. Electrical resistivity (ER) and compressive and tensile behavior of various mixes were studied experimentally under chloride, sulphate, and chloride-sulphate combined environmental conditions. Results obtained from various properties revealed that performance of fully MSS and FS containing ECC mixes was affected under aggressive substances at initial stages. The observations demonstrate that ECC containing SSP was durable and maintains better mechanical performance over fully MSS and FS containing mixes. This improvement finds a place in construction of hydraulic structures under aggressive environments.
\end{abstract}

Keywords: Durability; Electrical resistivity; Chemical attack; Stone slurry powder; Micro pores.

\section{INTRODUCTION}

Performance of cement-based composites not only depends on mechanical parameters but also on durability parameters which are prime concerns during designing of structures. The durability parameters of cementitious composite are based on the permeation, expansion, resistance to freeze-thaw, surface layer spalling, electrical resistance, and chemical attacks such as chloride and sulphate attack (Ozbay et al., 2013). The presence of chloride ions and sulphate ions in marine and seawater affects the durability performance of concrete structures, due to the chemical reaction between high concentration of ions and hydration product of cement-matrix (Li et al., 2018; Taylor et al., 2001; Al- Amoudi 2002; Santhanam et al., 2006; Al-Dulaijan et al., 2003; Neville 2012). Permeation of the ions into concrete structures leads to the poor durability performance, resulting into deterioration of structures (Sibbick et al., 2003; Salami et al., 2017; Skalny et al., 2002; Al-Amoudi, 1998; Liu et al., 2017 ). Generally, the performance of conventional concrete is measured on the strength parameters. In the last two decades, the development of skyscrapers is going on, which triggers the use of high strength concrete (HSC) in concrete structures. The use of HSC increases the brittleness of concrete. But, it propagates the cracks and their width. The growth of cracks results in poor durability performance of hydraulic concrete structures (Liuet al., $2017^{\mathrm{b}}$ ). In cement-based structures, thermal contraction, expansion, drying shrinkage, chemical attack, 
deformations, and mechanical loads, all are the possible reasons for cracking. These cracks in hydraulic concrete structures drastically accelerate the deterioration by connecting the pores and provide easy access for aggressive ions (chloride and sulphate ions) (ACI 224R, 2001; Sahmaran et al., 2007). Wider crack width significantly increases the diffusivity of aggressive ions, whereas, in narrow crack width the influence of aggressive ions was found negligible. The corrosion rate significantly increases, if the width of crack exceeds $100 \mu \mathrm{m}$. Therefore, controlled crack width is essential to enhance the life span and durability performance of hydraulic concrete structures under chloride, sulphate, and chloride-sulphate conditions. In conventional concrete, the controlled cracking is considered as a significant challenge. Numerous efforts like use of different types of materials, steel reinforcement, and temperature control have been made to control crack width in cement matrix. Cracking in concrete is almost inevitable due to its highly brittle nature under mechanical loadings and environmental conditions (Li et al., 2011; Sahmaran et al., 2008). Therefore, reliable control of crack width in concrete is tedious. However, to improve the durability performance of concrete structures under chemical attack and environmental conditions, a material with controlled crack width is required. Numerous researchers reported that the use of different types of fibers in concrete enhanced the strength as well as strain parameters and arrest the micro and macro level cracks (Anandan et al., 2019; Farooqi et al., 2018; Zia et al., 2017; Teng et al., 2018).

Cement-based materials are typical porous materials and also have some electrical performance. The concrete properties have strong relationship with conductivity and pore structure. Electrical resistivity is a superb nondestructive technique (NDT), used in modelling the penetration of aggressive agents in cementitious materials and as an indication of electrical charge in cement-based materials. Several studies claim electrical resistivity to be a key factor to indicate the permeability of concrete to aggressive substances, as resistivity is a function of concrete microstructure (Madani et al., 2014; Medeiros-Junior et al., 2016; Zivica et al., 1994). Numerous supplementary cementitious materials (SCM) such as fly ash (FA), ground granulated blast furnace slag (GGBFS), palm oil fuel ash (POFA), rice husk ash (RHA), and so on have been used to reduce the pore size in cementitious paste, produce a highly resistive cementitious material, and improve the durability performance of ECC under chemical attacks (Sahmaran et al., 2009; Hussain1994; Ramezanianpour et al., 2011).

ECC is one of cementitious materials that contain fibers as well as high amount of supplementary cementitious material (SCM) in mix design. ECC is a superb class of high performance fiber reinforced cementitious composite (HPFRCC) featuring high strain capacity (1-8\%) and constraint crack width (less than $100 \mu \mathrm{m}$ ). The low volume fiber fraction (approximately $2 \%$ of the volume of cementitious materials) has been used in ECC. The design of ECC relies on micromechanics of fiber bridging and crack extension. Under tensile loading, ECC exhibits extensive strain hardening behavior with multiple fine cracking (Singh et al., 2019a; Li, V.C 1998; Singh et al., $2019 \mathrm{~b}$ ). The high energy absorption capacity (approximately $30 \mathrm{KJ} / \mathrm{m} 2$ ) and ductile nature of ECC made it unique from other types of cementitious materials. The performance of parameters such as flexural capacity, compressive, tensile, toughness, and density depends on the types of the constituents used in the mix design (Li et al., 1998; Singh et al., 2019c). Minimal crack width of ECC arrests the penetration of aggressive ions in cement-matrix surface and also improves the durability performance and self-healing. Previous research studies on durability reported that the tight crack width of ECC greatly obstructs further deterioration of structures as compared to conventional concrete structures (Liu et al., 2017b; Abou-Zeid et al., 2001; Sahmaran et al., 2007). The standard ECC consists of Class-F fly ash, Portland cement, micro silica sand, oiled polyvinyl alcohol fiber, and polycarboxylic ether type (PCE) high range water reducing admixture (HRWRA). The durability performance of ECC under sulphate and chloride immersion has been investigated by various researchers.

Liu et al., 2017b characterized the tensile and compressive behavior of ECC under sulphate and sulphatechloride immersion. The experimental results reported that ECC exhibits more durable behavior than conventional concrete under sulphate and sulphate-chloride conditions. The findings demonstrated that ECC can be used as a protective layer to enhance the long-term durability performance of cement based hydraulic structures. Sahmaran et 
al., 2007, characterized the ECC properties under chloride exposure. It has been reported that ECC demonstrates low chloride diffusion coefficient and more durable behavior than mortar mix. Li et al., 2011 reported that ECC exhibits enhanced tensile ductility and durability under chloride immersion. Lepech et al., 2006, found that ECC is more durable under freeze-thaw cycles. Sahmaran et al., 2008, and Li et al., 2011, demonstrated that the presence of high alkaline and chloride environment did not affect the self-healing characterization of ECC, whereas, it improved the durability. Numerous investigations reported that durability performance of ECC significantly has been enhanced under exposure to aggressive ions, such as sulphate, chloride, sulphate-chloride immersion, freezethaw cycles, hot water immersion, alkali-silicate reaction, and de-icing salt exposures.

In this investigation, six ECC mixtures were prepared with the use of ground granulated blast furnace slag (GGBFS) as a supplementary cementitious material and stone slurry powder (SSP) as a substitution of fine aggregates (i.e., MSS and FS). Most of the durability investigations have been conducted with the use of fly ash till now. GGBFS is a by-product from iron and steel industries, whereas SSP is being generated from stone industry during cutting and sawing process of stones. The utilization of slag in ECC enhanced the tensile strain and deflection capacity. The presence of slag in ECC mixture provides a driving force for fiber dispersion and also improved the durability performance under sulphate and chloride immersion (Zhou et al., 2010). Ozbay et al., 2013, reported that ductility, sorptivity, water absorption, and porosity of ECC have been enhanced with the increase in quantity of slag. Ulubeyli et al., 2016, and Lakhani et al., 2014, reported that the use of stone waste in conventional concrete improved the durability performance of conventional concrete. The literature reported that limited studies have been carried out on ECC incorporating slag and SSP under chloride, sulphate, sulphate-chloride environment, and electrical performance.

\section{RESEARCH SIGNIFICANCE}

Numerous research studies have been carried out on durability performance of conventional concrete with the use of various supplementary materials such as fly ash, slag, marble powder, silica fume, and rice husk ash. But the limited research works have been carried out on durability performance of ECC with these waste materials. To protect the environment from harmful impact, utilization of solid waste products in huge amount is required. In this research work, industrial by-products (GGBFS and SSP) were utilized in excess amount to make an eco-friendly ECC. The objective of this research is to assess the effect of SSP and GGBFS in combination on the durability performance of ECC under aggressive ions. The durability performance of different ECC mixes has been evaluated experimentally under immersion in chloride, sulphate, and their combination. Present research provides a better platform for utilizing the GGBFS and SSP in construction industry. This work highlights the significance of GGBFS and SSP in durability performance of ECC under chemical exposures and also provides guidelines for design and applicability of ECC in hydraulic concrete structures.

\section{MATERIALS AND METHODS}

\section{Characterization of Materials}

Constituents used in this research work were Portland cement (PC) of grade 43, GGBFS, and SSP. Chemical compositions and physical properties of PC, GGBFS, and SSP have been given in Table1. Micro silica sand (MSS) and natural river fine sand (FS) with maximum size of 175 micron and 600 micron, respectively, have been used as fine aggregate in ECC mixtures. SSP was used as substitution of MSS and FS at levels $25 \%$ and $50 \%$ for each sand; whereas, GGBFS (55\% of the total cementitious material) was used as cementitious material. Polycarboxylic-ether type high range water reducer (HRWRA) was added with water in solid content to achieve the proper rheological performance. The polyvinyl alcohol (PVA) fiber used in the present research was of $12 \mathrm{~mm}$ length, $39 \mu \mathrm{m}$ diameter, $1300 \mathrm{~kg} / \mathrm{m}^{3}$ density, $1600 \mathrm{MPa}$ tensile strength, $42.8 \mathrm{GPa}$ Young's modulus, and 7\% elongation. To reduce 
the chemical bond between fiber-matrix and friction, the oil coat (1.2\% by weight) was done on surface of the fibers. A constant fiber volume fraction ( $2 \%$ by weight of cementitious materials) was used in all six mixes.

Table 1. Characteristics of PC, GGBFS, and SSP.

\begin{tabular}{|c|c|c|c|}
\hline Chemical analysis & GGBFS & PC & SSP \\
\hline $\mathrm{SiO}_{2}$ & 38.20 & 20.75 & 1.40 \\
\hline $\mathrm{CaO}$ & 36.94 & 66.96 & 54.70 \\
\hline $\mathrm{Al}_{2} \mathrm{O}_{3}$ & 17.02 & 7.52 & - \\
\hline $\mathrm{MgO}$ & 5.24 & 1.03 & 0.24 \\
\hline $\mathrm{Na}_{2} \mathrm{O}$ & 0.29 & 1.22 & - \\
\hline $\mathrm{K}_{2} \mathrm{O}$ & 0.19 & 0.41 & - \\
\hline $\mathrm{SO}_{3}$ & 2.12 & 2.12 & 43.66 \\
\hline $\mathrm{LOI}^{*}$ & - & - & 2.78 \\
\hline Density & 2.82 & 3.11 & \\
\hline
\end{tabular}

* Loss of ignition

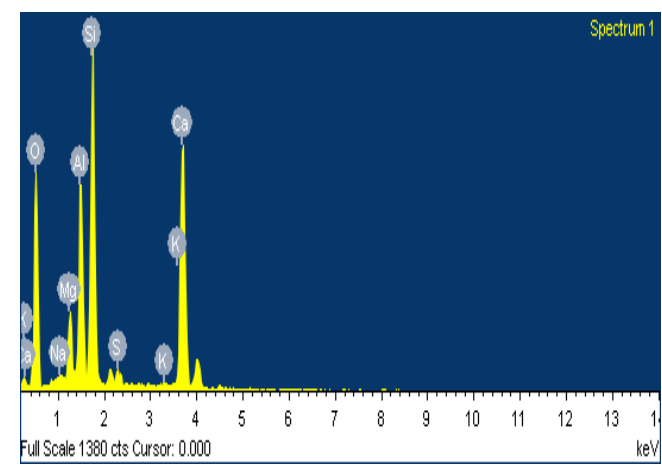

(a)

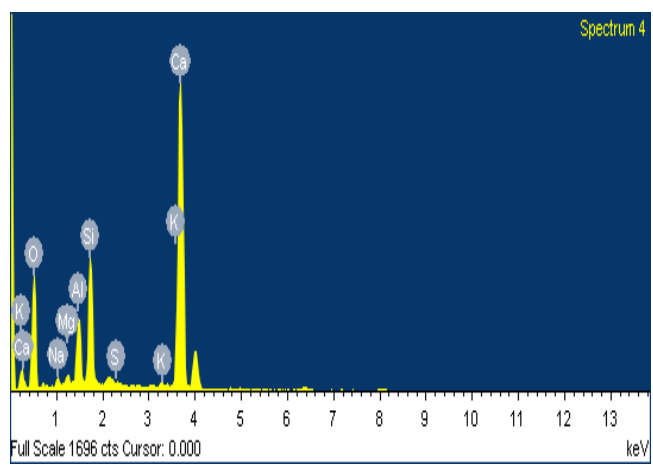

(b)

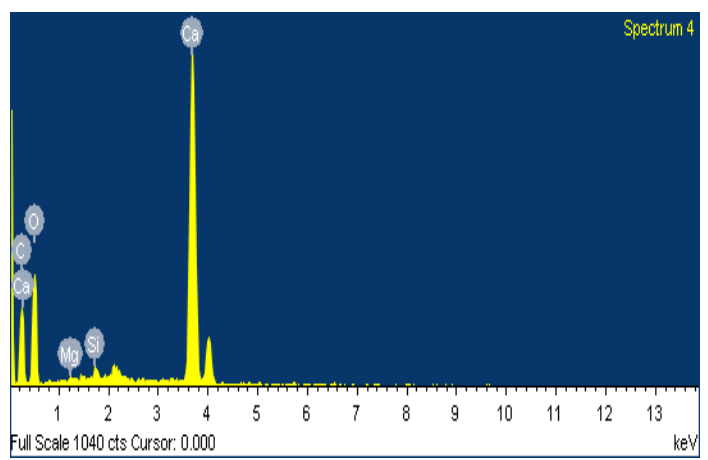

(c)

Figure 1(a). Energy dispersive X-ray spectroscopy analysis of (a) GGBFS, (b) PC, and (c) SSP. 


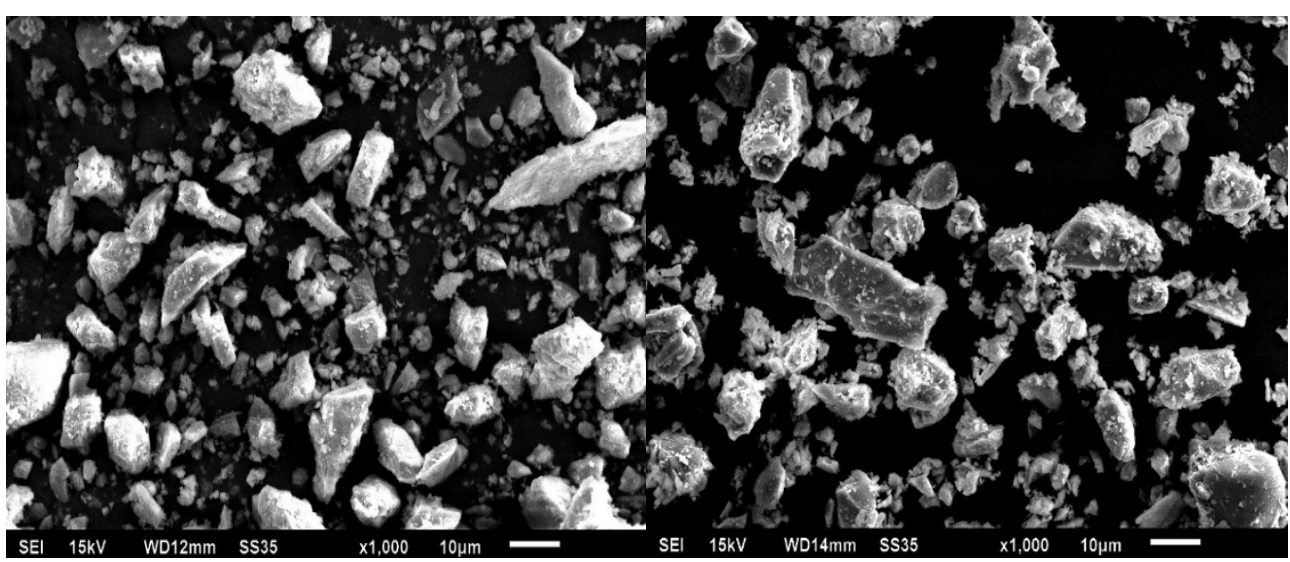

(a)

(b)

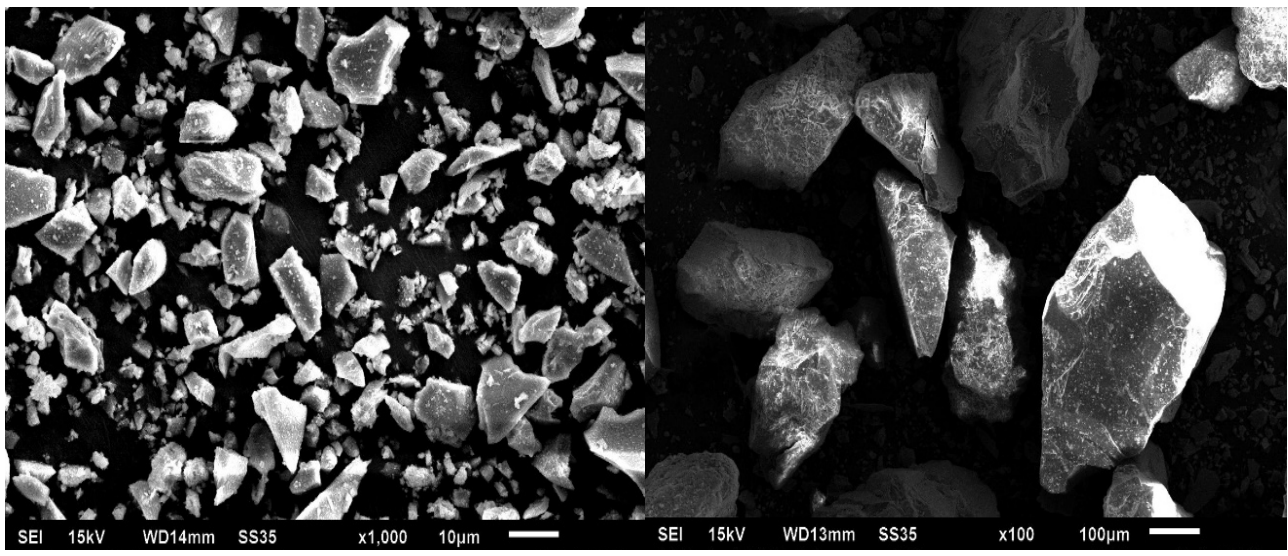

(c)

(d)

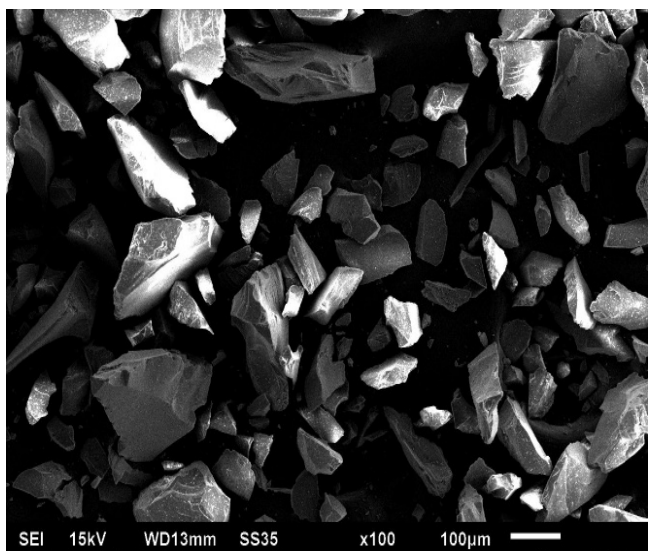

(e)

Figure 1(b). Micrographs of scanning electron microscopy: (a) SSP, (b) PC, (c) GGBFS, (d) FS, and (e) SS. 


\section{Mixture Proportions}

To analyze the effect of GGBFS and SSP in combination under different exposures, six cementitious mixes were prepared with the subrogation of MSS and FS as listed in Table 2.

Table 2. Mix proportions of ECC incorporating industrial by-products.

\begin{tabular}{|c|c|c|c|c|c|c|c|c|}
\hline \multicolumn{9}{|c|}{ Constituents } \\
\hline Mix reference & PC & $\begin{array}{c}\text { GGBF } \\
\text { S }\end{array}$ & MSS & FS & SSP & w/b & $\begin{array}{c}\text { PVA } \\
(\%)\end{array}$ & $\begin{array}{c}\text { HRWR } \\
\text { A (\%) }\end{array}$ \\
\hline MSS & 1 & 1.2 & 0.8 & ----- & ---- & 0.27 & 2 & 0.45 \\
\hline MSS_25 SSP & 1 & 1.2 & 0.6 & ----- & 0.2 & 0.27 & 2 & 0.45 \\
\hline MSS_50 SSP & 1 & 1.2 & 0.4 & ----- & 0.4 & 0.27 & 2 & 0.45 \\
\hline FS & 1 & 1.2 & ----- & 0.8 & ---- & 0.27 & 2 & 0.45 \\
\hline FS_25 SSP & 1 & 1.2 & ----- & 0.6 & 0.2 & 0.27 & 2 & 0.45 \\
\hline FS_50 SSP & 1 & 1.2 & ----- & 0.4 & 0.4 & 0.27 & 2 & 0.45 \\
\hline
\end{tabular}

\section{Fabrication and Curing Process}

Power driven mortar mixer was used in preparing all the cementitious mixtures. All solid constituents were added into the drum in dry state, and the mixer was rotated until adequately mixed. Then, water and HRWRA were added slowly into the mixed constituents until stirred state was achieved. And at the end, fibers were added slowly and the mixer was rotated until fibers were evenly distributed. The homogenous mix was poured into the moulds of $70.6 \mathrm{~mm} \times 70.6 \mathrm{~mm} \times 70.6 \mathrm{~mm}$ cubes (for electrical resistivity and compressive strength) and $310 \mathrm{~mm} \times 100 \mathrm{~mm} \times$ $20 \mathrm{~mm}$ dog bone shaped specimen (for tensile parameters), placed at room temperature for $24 \mathrm{~h}$. Then, all the casted specimens were demoulded and placed inside the water curing tank for required age. After 28 days of water curing, as per testing requirements, specimens were immersed into the following solutions: $5 \%$ (by weight) $\mathrm{Na}_{2} \mathrm{SO}_{4}$ solution, $5 \%$ (by weight) $\mathrm{NaCl}$ solution, and $5 \%$ (by weight) $\mathrm{Na}_{2} \mathrm{SO}_{4}+3 \%$ (by weight) $\mathrm{NaCl}$ for 28, 62, and 152 days, and the rest of the specimens remained in water curing tank for reference.

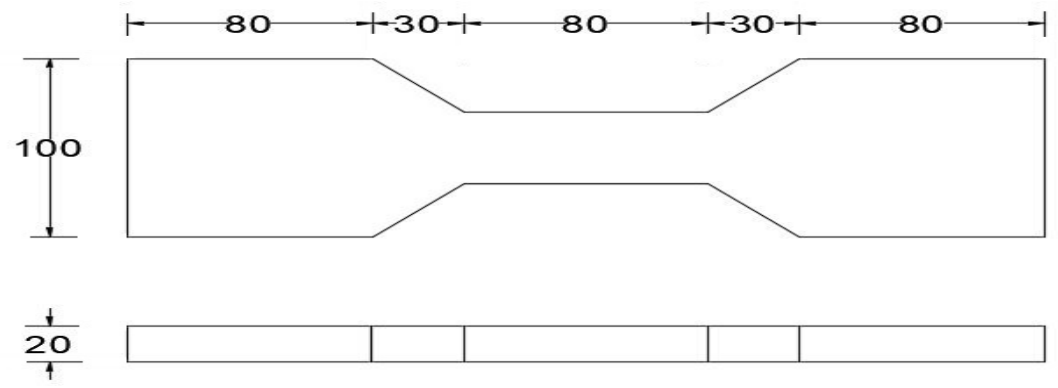

All the dimensions in 'mm'.

Figure 2. Schematic view of dog bone specimens. 


\section{PROCEDURE AND SETUP FOR TESTING}

\section{Compression Behaviour}

To study the compressive behavior of various mixtures against exposure to chloride attack, sulphate attack, sulphate-chloride attack mortar cubes (ASTM C1012, 2012) of the aforementioned dimensions were used and tested in compression testing machine as per IS 516:1959, 2006 and BS-EN-12390-3, 2009 specifications.

\section{Tensile Behavior}

In the present study, dog bone shaped specimens shown in Fig. 2 were used to analyze the tensile behavior of all six mixes, under different environmental conditions. The universal testing machine (UTM) at loading rate 0.2 $\mathrm{mm} /$ minute was used to analyze the tensile behavior. The wedge face of specimen was gripped in the machine and gauge length was used to record the tensile strength and strain.

\section{Electrical Resistivity}

During measurement of electrical resistivity of cement matrix, moving ions are taken as an indication of diffusion of ions. Electrical resistivity (ER) can be used as durability indicator, and the correlation between ER and corrosion rate has been given in Table 3. The ER of ECC specimens was recorded via a two-point method. For measuring the movement of ions in various mixes, cube specimens were used. The transport property of various mixes was recorded on cement matrix cubes. Moist sponge was used on top and bottom surface of cement matrix cubes to establish a stable electrical connection between two parallel plates. The alternating current was measured on set of three mortar cubes for each mix with the help of True RMS multimeter, model number U1252B, manufactured by Keysight. The electrical resistivity of the cementitious composite, $\rho$, can then be calculated on mortar cubes by the following formula.

$\rho=\mathrm{R} \frac{A}{L}(k \Omega-c m)$

where $\mathrm{A}$ is the area of the sample $\left(\mathrm{cm}^{2}\right), \mathrm{L}$ is the length of the sample, and $\mathrm{R}(k \Omega)$ is the resistance of the sample which can be obtained from the multimeter.

Table 3. Corelation between ER and corrosion rate (Broomfield, 2007; ACI 222R-01, 2010).

\begin{tabular}{|c|c|c|c|c|}
\hline ER $(\mathbf{k} \Omega-c m)$ & $>\mathbf{2 0}$ & $\mathbf{1 0 - 2 0}$ & $\mathbf{5 - 1 0}$ & $<\mathbf{5}$ \\
\hline $\begin{array}{c}\text { Corrosion } \\
\text { Threat }\end{array}$ & Low & Low to moderate & High & Very high \\
\hline
\end{tabular}




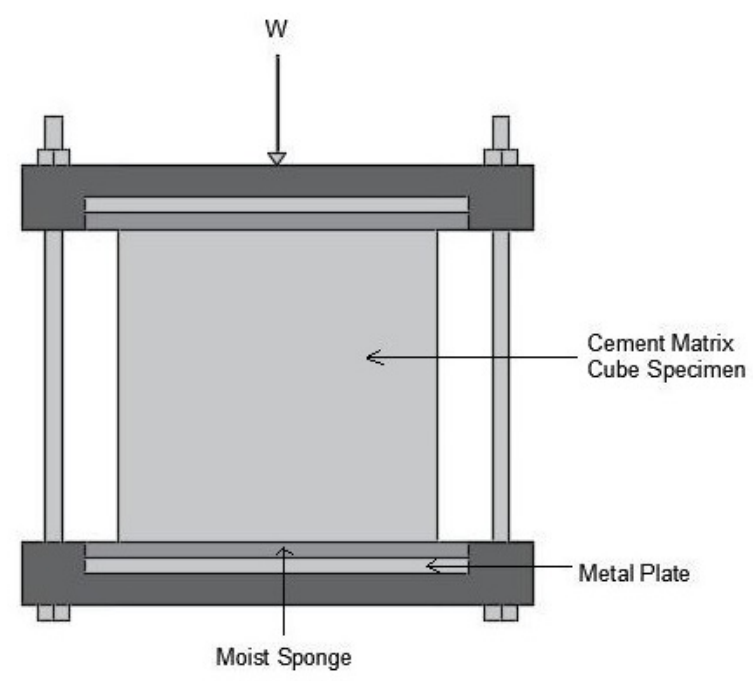

Figure 3. Electrical resistivity setup.

\section{RESULTS AND DISCUSSION}

\section{Visual Inspection}

The surface of hardened ECC specimens containing SSP was smooth and better finished than fully MSS and FS blended mix. No physical signs were visible on hardened ECC specimens when exposed to different chemical solutions. At $(28+62)$ and $(28+152)$ day's exposure to aggressive environment $\left(5 \% \mathrm{Na}_{2} \mathrm{SO}_{4}\right.$ solution, $5 \% \mathrm{NaCl}$ solution, and $5 \% \mathrm{Na}_{2} \mathrm{SO}_{4}+3 \% \mathrm{NaCl}$ ), white covering was observed on the surface of the specimens.

\section{Compressive Behavior}

The compressive strength (CS) of various ECC mixtures specimens stored under different exposure conditions, that is, (a) $5 \% \mathrm{NaCl}$ solution, (b) $5 \% \mathrm{Na}_{2} \mathrm{SO}_{4}$ solution, and (c) $5 \% \mathrm{Na}_{2} \mathrm{SO}_{4}+3 \% \mathrm{NaCl}$ solution for 28 days, 62 days, and 152 days was observed and compared with water cured specimens at 56 days, 90 days, and 180 days, respectively. Figure 4 showed that the CS of all the six ECC mixtures increased at 56 days, 90 days, and 180 days of water curing due to continuous hydration process of cement and pozzolanic activity of GGBFS that may be effective in long term and requires long period of curing (Ozbayet al., 2013). The CS of fully MSS blended mix was observed higher than fully FS blended mix. Substitution of MSS at level $25 \%$ and $50 \%$ enhanced the CS by $7.17 \% ; 7.41 \% ; 6.86 \%$ and $4.92 \% ; 5.64$; and $4.49 \%$ after 56 days; 90 days; and 180 days of water curing, respectively. Replacement of FS at $25 \%$ and $50 \%$ enhanced the CS by $9.37 \% ; 8.43 \% ; 9.52 \%$ and $7.03 \% ; 6.13 \%$; and $7.49 \%$ after 56 days; 90 days; and 180 days of water curing. Maximum enhancement in CS was observed in FS_25 SSP mix that was due to the finer pore structure of SSP. The optimum CS was found when $25 \%$ SSP was charged along with mix containing MSS and also mix containing FS under water curing at all curing ages.

In case of chloride attack, slight increase was observed in CS of fully MSS blended mix proportion; whereas, the slight decrease was observed in fully FS blended mix proportion at 28-day and 62-day exposure period. After 152 days, chloride exposure increased the CS of fully MSS and FS blended mix proportion by $3.37 \%$ and $1.84 \%$, respectively. Replacement of MSS with SSP at level $25 \%$ and $50 \%$ increased the CS by $1.27 \%$; $2.55 \%$; and $2.34 \%$ and $2.23 \% ; 3.75 \%$; and $3.22 \%$ after 28 days, 62 days, and 152 days of chloride exposure, respectively. FS 
substitution with SSP at 25\% and 50\% increased the CS by $1.62 \% ; 3.02 \%$; and $2.57 \%$ and $1.16 \%$; $4.05 \%$; and $3.73 \%$ after 28 days, 62 days, and 152 days of chloride exposure, respectively. The highest CS was observed for mix proportion FS_25 SSP; whereas, the higher percentage increase in CS was observed in mix proportion FS_SSP 50 after 62 days exposure.

In case of sulphate exposure at 28 days and 62 days, no slight change was observed in CS of fully MSS blended mix; whereas, the CS of fully FS blended mix showed a slightly decreasing trend, that is, $1.17 \%$ and $2.73 \%$ after 28 days and 62 days of exposure, respectively. Utilization of SSP as both types of sand replacement at $25 \%$ and 50\% in cementitious mix enhanced the CS. Highest value of CS was observed in mix proportion FS_25 SSP. Whereas, the higher percentage increase in CS was observed in mix proportion MSS_SSP 50, that is, 1.36\% at 28 days of exposure. And at 62 days of exposure, highest value of CS was observed in mix proportion FS_25 SSP, whereas higher percentage increase in CS was observed in mix proportion FS_SSP 50, that is, 3.03\%. After a 152day sulphate attack, the enhancement in CS of all the six mix proportions was observed. The optimum CS in both cases, that is, MSS and FS, blended mix proportions were found when 25\% SSP was charged.; Whereas, higher percentage increase in CS was observed in mix proportion FS_SSP 50, that is, $2.65 \%$.

In case of combined chloride and sulphate attack, slight increase was observed in CS of fully MSS blended mix proportion; whereas, no obvious change was observed in fully FS blended mix proportion after 28-day and 62day exposure period. After 152 days, combined chemicals exposure increased the CS of fully MSS and FS blended mix by $4.24 \%$ and $2.64 \%$, respectively. Utilization of SSP as MSS replacement at $25 \%$ and $50 \%$ increased the CS by $1.65 \% ; 3.14 \%$; and $3.39 \%$ and $2.79 \% ; 4.78 \%$; and $5.02 \%$ after 28 days 62 days and 152 days of exposure, respectively. Substitution of FS with SSP at $25 \%$ and $50 \%$ increased the CS by $2.12 \%$; $3.98 \%$; and $4.08 \%$ and $2.05 \%$; $4.66 \%$; and $4.90 \%$ after 28 days, 62 days and 152 days of combined exposure, respectively. The highest CS was observed for mix proportion FS_25 SSP; whereas, higher percentage increase in CS was observed in mix proportion MSS_SSP 50 after 152 days of combined exposure, that is, $5.02 \%$.

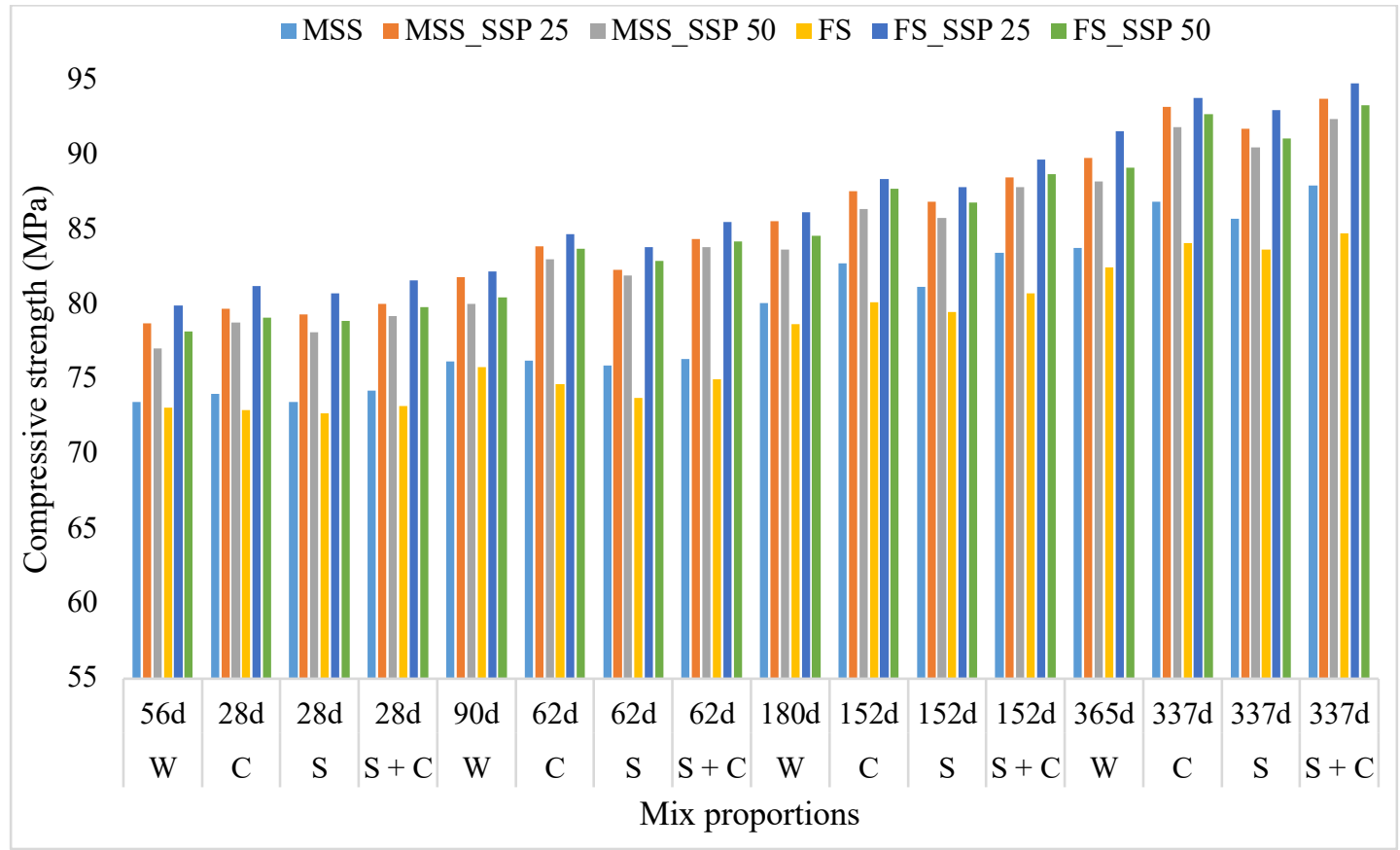

Figure 4. CS behavior under different environmental conditions at vario0us ages. 
The optimum mix proportion was found FS_25 SSP in terms of resistance against various chemical attacks. The CS results of various mixes showed that the utilization of SSP waste in ECC fills the micro pores and provides resistance against various chemical attacks. The continuous hydration process of cement and pozzolanic activity of GGBFS that may be long term diffused the chemical ions and formed ettringite, which may contribute to strength achievements in longer term (Ozbay et al., 2013; Liu et al., 2017 ; Sahmaran et al., 2008).

Numerous researchers claimed that chloride attack is not serious compared to sulphate attack. This indicates gain in strength in $\left(\mathrm{Na}_{2} \mathrm{SO}_{4}+\mathrm{NaCl}\right)$ solution cured specimens, due to the presence of chloride ions that slowed down the sulphate ions reaction (Liu et al., 2017 ). Increase in strength in SSP containing mixes due to fine pore structure of SSP that attributed to a micro filling effect. In Figure 1(b), SEM photographs of various materials used in this study depict that the particles size of SSP is very few as compared to both types of sand's particles size. On the other hand, the slight decrease in strength of fully MSS and FS blended mix proportions was observed due the high size of particles of sands than SSP that may develop some micro voids with hydrophilic nature of PVA fiber.

\section{ELECTRICAL RESISTIVITY}

The electrical resistance (ER) of various mix proportions under laboratory environment and different aggressive substances has been shown in Figure 5. The ER of fully MSS blended mix proportion was observed to be higher than fully FS blended mix proportion, which may be due to fine particles of MSS than FS. Increase in the amount of SSP as substitution of both types of sands (MSS \& FS) in cement matrix increased the ER of ECC mixes. The substitution of MSS with SSP at levels $25 \%$ and $50 \%$ increased the ER by $9.24 \%, 7.21 \%$, and $11.60 \%$ and $19.04 \%, 12.37 \%$, and $20.19 \%$ of water cured specimens after 56 days, 90 days, and 180 days, respectively. Partial subrogation of FS with SSP at levels $25 \%$ and $50 \%$ increased the ER by $13.72 \%, 9.71 \%$, and $15.17 \%$ and $16.86 \%, 17.62 \%$, and $21.87 \%$ of water cured specimens after 56 days, 90 days, and 180 days, respectively. The increase in ER may be attributed to finer pore structure of SSP resulting densification of the whole structure of cement matrix. The optimum ER in both cases, that is, MSS and FS blended mix proportions was found when $50 \%$ SSP was charged along with this.

Under chloride attack, ER of fully MSS and FS blended mix proportions reduced by $8.95 \% ; 5.35 \%$ and $11.46 \% ; 7.44 \%$ after 28 days and 62 days of exposure period. And after 152 days of chloride exposure, the ER of fully MSS and FS blended mix proportions was almost same as that of water cured specimens at the same age. No slight change was observed after 28 days and 62 days of exposure with the utilization of SSP as replacement of both types of sands at $25 \%$. At $50 \%$, SSP substitution for each type of sand slightly enhanced the ER of various mixes after 28 days and 62 days of exposure. The maximum percentage of ER enhancement was found in FS_SSP50, that is, i.e. $6.26 \%$ after 62 days of exposure. After 152 days of exposure, the ER of SS_SSP25, SS_SSP50, FS_SSP25, and FS_SSP50 mix proportions was increased by $4.30 \%, 4.86 \%, 6.75 \%$, and $7.52 \%$, respectively. Results of ER under chloride exposure showed increase in utilization percentage of SSP as both types of sand enhanced the resistance against chloride attack.

In case of sulphate attack, ER of fully MSS and FS blended mix proportions was reduced by 3.35\%; 3.30\%, and $6.62 ; 4.07 \%$ after $28 \mathrm{~d}$ and $62 \mathrm{~d}$ exposure period. And after 152 days of immersion, ER of fully MSS and FS blended mix proportions was increased by $1.58 \%$ and $4.17 \%$, respectively. Utilization of SSP as sand replacement (MSS \& FS) enhanced the ER and provided resistance against sulphate exposure. Replacement of MSS at $25 \%$ and $50 \%$ with SSP enhanced the ER by $3.83 \% ; 8.16 \%$; and $9.84 \%$ and $5.29 \% ; 7.89 \%$; and $8.23 \%$ after 28 days; 62 days; and 152 days of immersion. Substitution of FS with SSP at $25 \%$ and $50 \%$ enhanced the ER by $1.97 \% ; 4.80 \%$; and $11.34 \%$ and $9.82 \% ; 13.23 \%$; and $10.70 \%$ after 28 days; 62 days; and 152 days of sulphate immersion. The optimum percentage of SSP utilization was found to be $50 \%$ in both types of sand replacements. 
During combined chemical (chloride and sulphate) immersion, ER of fully MSS and FS blended mix proportions was decreased by $6.15 \% ; 4.64 \%$ and $9.56 \% ; 6.38 \%$ after 28 days and 62 days of exposure; whereas, after 152 days, the ER of both the mixes was almost same as that of water cured specimens at $180 \mathrm{~d}$. Replacement of MSS at $25 \%$ and $50 \%$ with SSP enhanced the ER by $2.30 \%$; $5.96 \%$; and $7.82 \%$ and $4.11 \% ; 5.31 \%$; and $6.74 \%$ after 28 days; 62 days; and 152 days of combined chemical (chloride and sulphate) attack. Substitution of FS with SSP at $25 \%$ and $50 \%$ enhanced the ER by $0.91 \% ; 3.17 \%$; and $8.98 \%$ and $5.77 \% ; 8.68 \%$; and $9.17 \%$ after 28 days; 62 days; and 152 days of combined chemical (chloride and sulphate) attack. The optimum ER was found in FS_SSP50 mix proportion at all exposure durations.

The ER results from the various exposure conditions analyzed in this work revealed that chloride attack is more serious than sulphate attack for ER performance. The micro pore structure of SSP fills the voids present on the surface of the randomly distributed PVA fibers and protects the surface of fiber from chemical substances up to some limit i.e. due to which increment in the ER of SSP blended mixes was observed. Due to the presence of GGBFS, hydration process of matrix continued for longer period which is responsible for the densify state and ER enhancement up to 180 -day water curing. The values of ER were observed minimum $(42.50 \mathrm{k} \Omega$-cm) in fully FS blended mix proportion at 56 days of chloride exposure and maximum $(133.71 \mathrm{k} \Omega-\mathrm{cm})$ in MSS_SSP50 mix proportion at 152 days of sulphate exposure. All the values of ER were very high which correspond to very low corrosion rate (Broomfield, 2007). From the experimental results, it has been observed that utilization of SSP waste in ECC enhanced the electrical resistivity of various mixes under different environmental conditions.

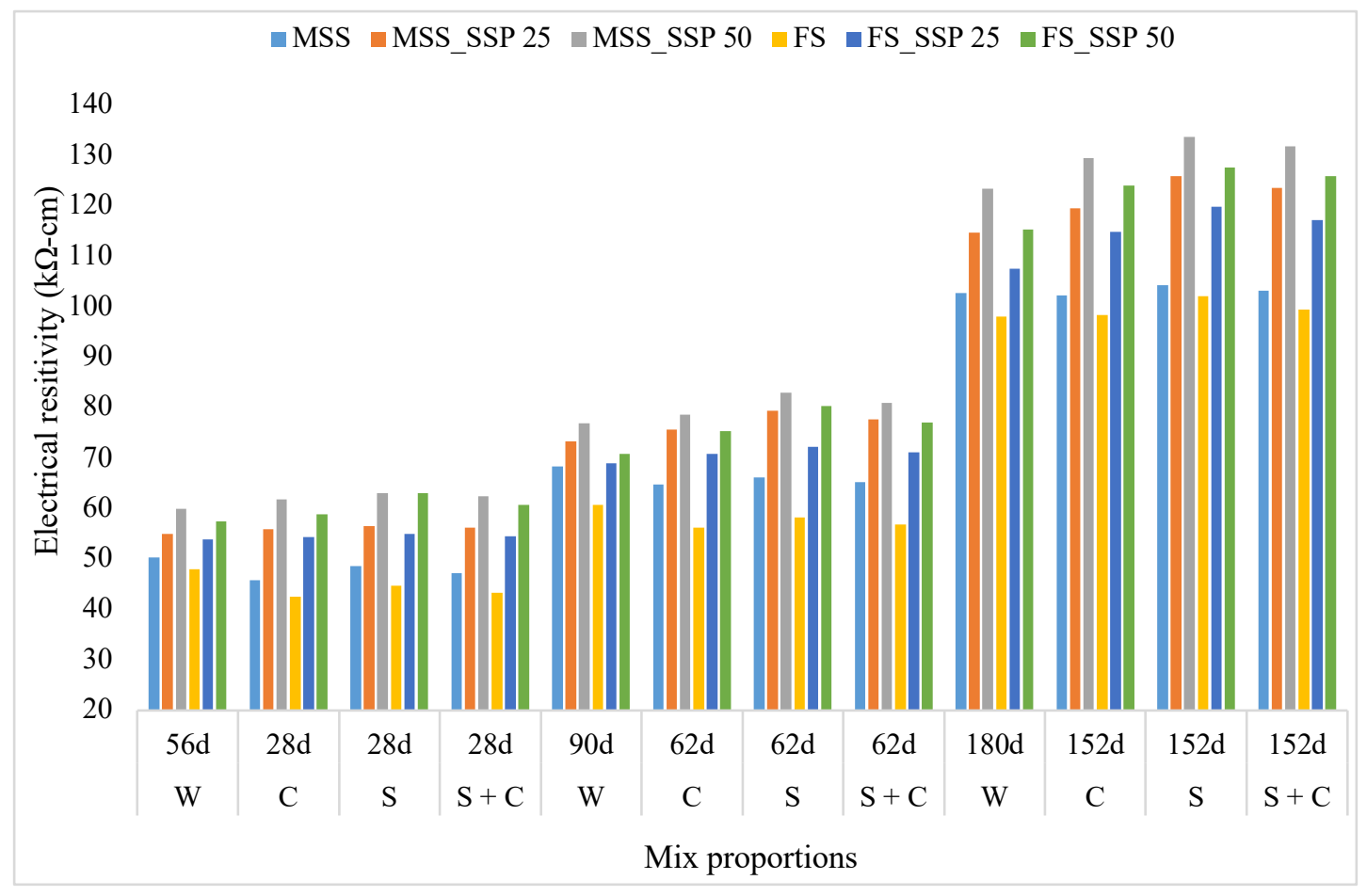

Figure 5. ER behavior under different environmental conditions at various ages. 


\section{TENSILE BEHAVIOR}

\section{Tensile Strength}

Figure 6 presents the tensile strength (TS) of various ECC mix specimens under 56 days, 90 days, and 180 days of water curing and chemical exposure. TS of fully MSS blended mix was slightly higher than fully FS blended mix under laboratory environment. Substitution of MSS with SSP at levels $25 \%$ and $50 \%$ enhanced TS by $11.62 \%$; $9.53 \%$; and $10.42 \%$ and $3.08 \% ; 6.2 \%$; and $2.89 \%$ after 56 days; 90 days; and $180 \mathrm{~d}$ of water curing, respectively. Partial subrogation of FS with SSP at levels $25 \%$ and $50 \%$ increased the TS by $18.93 \%$; $13.94 \%$; and $17.2 \%$ and $12.45 \% ; 7.12 \%$; and $10.74 \%$ after 56 days and 90 days of water curing, respectively. TS increment in SSP containing mixes was may be due to fine pore structure of SSP, acting as a gel when mixed with ECC mixture, that is, filled the micro voids present on the surface of hydrophilic nature of PVA fiber. The optimum TS in both cases, that is, MSS and FS blended mix proportions, was found when 50\% SSP was charged along with this.

In case of chloride attack, the TS of fully MSS and FS blended mix proportion was reduced by $6.36 \%$; $1.61 \%$ and $5.34 \% ; 6.82 \%$ after 28 days; 62 days of exposure; whereas, at 152 days of exposure, TS increased by $4.52 \%$ and $5.15 \%$. Utilization of SSP in MSS blended mix proportion at $25 \%$ and $50 \%$ enhanced the TS by $1.63 \%$; $5.27 \%$; and $7.82 \%$ and $1.86 \% ; 8.98 \%$; and $11.71 \%$ after 28 days; 62 days; 152 days of chloride exposure, respectively. Substitution of FS with SSP at $25 \%$ and $50 \%$ enhanced the TS by $2.51 \% ; 7.81 \%$; and $10.26 \%$ and $3.20 \%$; $9.41 \%$; and $13.58 \%$ after 28 days; 62 days; 152 days of exposure period, respectively. The optimum TS was found in $25 \%$ SSP blended mix along with FS. The long term pozzolanic reaction of GGBFS and continuous cement hydration process diffused the chloride ions in the micro pores, and reaction of these ions with hydration products form ettringite, which may be responsible for strength achievements.

During sulphate immersion, the TS of fully MSS and FS blended mix proportion reduced by $7.59 \% ; 4.33 \%$ and $8.09 \% ; 9.79 \%$ after 28 days; 62 days of exposure; whereas, at 152 days, exposure increased by $2.33 \%$ and $4.68 \%$, respectively. At $25 \%$, substitution of MSS and FS with SSP reduced the TS by $2.5 \%$ and $0.95 \%$ after 28 days of exposure; whereas at 62 days; 152 days, exposure increased the TS by $1.84 \% ; 2.36 \%$ and $3.90 \% ; 3.42 \%$, respectively. The $50 \%$ utilization of SSP in MSS blended mix proportion did not show slight change in TS after 28 days of exposure; whereas at 62 days and 152 days, exposure increased the TS by $4.81 \%$ and $4.68 \%$, respectively. Subrogation of FS with SSP at 50\% enhanced the TS by 3.88\%, 5.26\%, and 5.43\% after 28 days, 62 days, and 152 days of chloride exposure. The optimum mix proportion was found FS_SSP 25 at all ages; whereas, the enhancement in TS was observed up to $50 \%$ SSP utilization along with each type of sand.

During the combined attack (chloride + sulphate) of chemicals, the TS of fully MSS blended mix proportion was enhanced by $1.08 \%, 1.87 \%$, and $7.27 \%$ after 28 days, 62 days, and 152 days of exposure, respectively. The TS of fully FS blended mix proportion was reduced by 3.23\%, 1.48\% at 28 days, 62 days of exposure, and afterwards at 152 days, exposure period increased by $3.29 \%$. Utilization of SSP in MSS blended mix proportion at $25 \%$ and $50 \%$ enhanced the TS by $4.44 \% ; 5.80 \%$; and $5.34 \%$ and $5.25 \% ; 11.23 \%$; and $10.67 \%$ after 28 days; 62 days; and 152 days sulphate exposure, respectively. Substitution of FS with SSP at $25 \%$ and $50 \%$ enhanced the TS by $5.03 \%$; $8.59 \%$; and $6.84 \%$ and $7.05 \% ; 12.04 \%$; and $9.44 \%$ after 28 days; 62 days; 152 days of exposure period, respectively. The optimum TS in both cases, that is, MSS and FS blended mix proportions, was found when $25 \%$ SSP was charged along with both, under combined chemical exposure. The presence of chloride mitigates the sulphate exposure, which may be responsible for strength achievement under combined attack. Micro filling effect of SSP declines the chemical exposure and improves the fiber-matrix interface, which provides higher fiber bridging strength. 


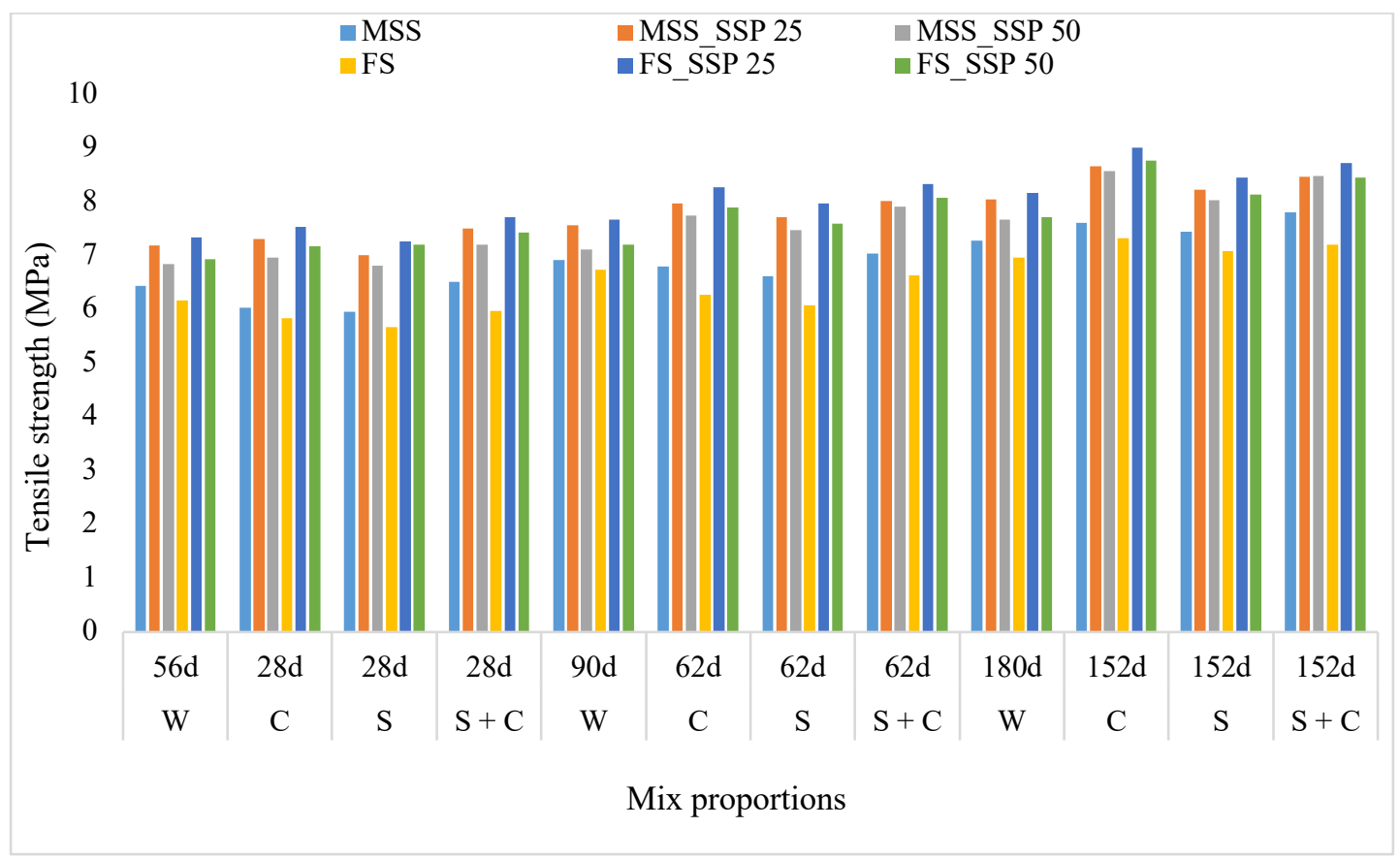

Figure 6. TS behavior under different environmental conditions at various ages.

\section{Tensile Strain}

Fig. 7 shows the tensile strain of various mixes of ECC specimens under different exposure conditions after 56 days, 90 days, and 180 days of curing, respectively. Tensile strain of fully MSS blended mix was slightly higher than fully FS blended mix under laboratory environment. Substitution of MSS with SSP at levels 25\% and 50\% improved the tensile strain by $7.59 \%, 13.36 \%$, and $8.05 \%$ and $13.8 \%, 24.2 \%$, and $18.01 \%$ after 56 days, 90 days, and 180 days of water curing, respectively. Results of partial substitution of FS with SSP at levels $25 \%$ and $50 \%$ revealed the increase in tensile strain by $10.11 \%, 11.73 \%$, and $13.09 \%$ and $16.47 \%, 20.4 \%$, and $24.4 \%$ after 56 days, 90 days, and 180 days of water curing. The optimum mix proportion was found MSS_SSP50 at 56 days and 90 days of water curing; whereas, at 180 days of curing, FS_SSP50 showed maximum tensile strain.

Chloride exposures after 28 days and 62 days reduced the tensile strain of fully MSS blended mix proportion by $5.35 \%$ and $3.96 \%$; whereas, after 152 days, exposure increased by $3.08 \%$. Chloride exposure also affects the tensile strain of fully FS blended mix proportion. That is, tensile strain reduced by $4 \%$ and $4.34 \%$ after 28 days and 62 days. After 152 days, exposure improved by 5.68\%. Combined exposure of both chemicals enhanced the tensile strain. Utilization of SSP in MSS blended mix proportion at 25\% and 50\% improved the tensile strain by $2.90 \%$; $6.11 \%$; and $6.35 \%$ and $1.96 \% ; 3.18 \%$; and $8.04 \%$ after 28 days; 62 days; and 152 days, respectively. Partial substitution of FS with SSP at $25 \%$ and $50 \%$ enhanced the tensile strain by $2.99 \% ; 5.48 \%$; and $8.30 \%$ and $3.43 \%$; 4.24\%; and 10.71\% after 28 days; 62 days; and 152 days, respectively. The finer particles of SSP in ECC mix behave as a gel, which protects the fiber surface from chloride attack that may be responsible for tensile strain enhancement.

During sulphate immersion, the tensile strain of fully MSS and FS blended mix proportions was reduced by $8.03 \% ; 7.92 \%$; and $3.80 \%$ and $6.82 \% ; 8.16 \%$; and $1.72 \%$ after 28 days; 62 days; and 152 days, respectively. Substitution of MSS and FS with SSP at 25\% showed slight decrease in tensile strain at initial stage (28 days of 
exposure), that is, $2.07 \%$ and $5.56 \%$, respectively. The tensile strain of MSS and FS blended mixes along with $25 \%$ SSP improved by $3.71 \% ; 4.82 \%$ and $3.20 \% ; 4.80 \%$ after 62 days; 152 days of exposure, respectively. Substitution of MSS with $50 \%$ SSP improved the tensile strain by $1.18 \%, 1.40 \%$, and $6.22 \%$ after 28 days, 62 days, and 152 days of sulphate exposure, respectively. Subrogation of FS with $50 \%$ SSP improved the tensile strain by $1.82 \%$, $1.70 \%$, and $8.33 \%$ after 28 days, 62 days, and 152 days of exposure period, respectively. The optimum tensile strain in both cases, that is, MSS and FS blended mix proportions, was found when $50 \%$ SSP was charged along with this. Reduction in tensile strain of fully MSS and FS blended mix proportions may be attributed to the change in the fiber-matrix interfacial properties. The presence of finer particles of SSP covering the fiber surface by filling voids present on this may promote the ductile nature of ECC under humid environment.

Under combined exposure of both chemicals (chloride + sulphate), the tensile strain showed improvement at all curing ages. The tensile strain of fully MSS and FS blended mix proportions increased by $7.14 \%$; $7.92 \%$; and $6.16 \%$ and $5.64 \%$; 3.31\%; and 9.13\% after 28 days; 62 days; and 152 days of combined exposure, respectively. Substitution of MSS and FS with 25\% SSP improved the tensile strain by $6.85 \% ; 12.50 \%$; and $9.00 \%$ and $7.69 \%$; $8.40 \%$; and $11.80 \%$ after 28 days; 62 days; and 152 days, respectively. Substitution of SSP at $50 \%$ with MSS and FS improved the tensile strain by $7.06 \% ; 4.38 \%$; and $10.84 \%$ and $7.88 \% ; 6.78 \%$; and $15.47 \%$ after 28 days; 62 days; and 152 days, respectively.

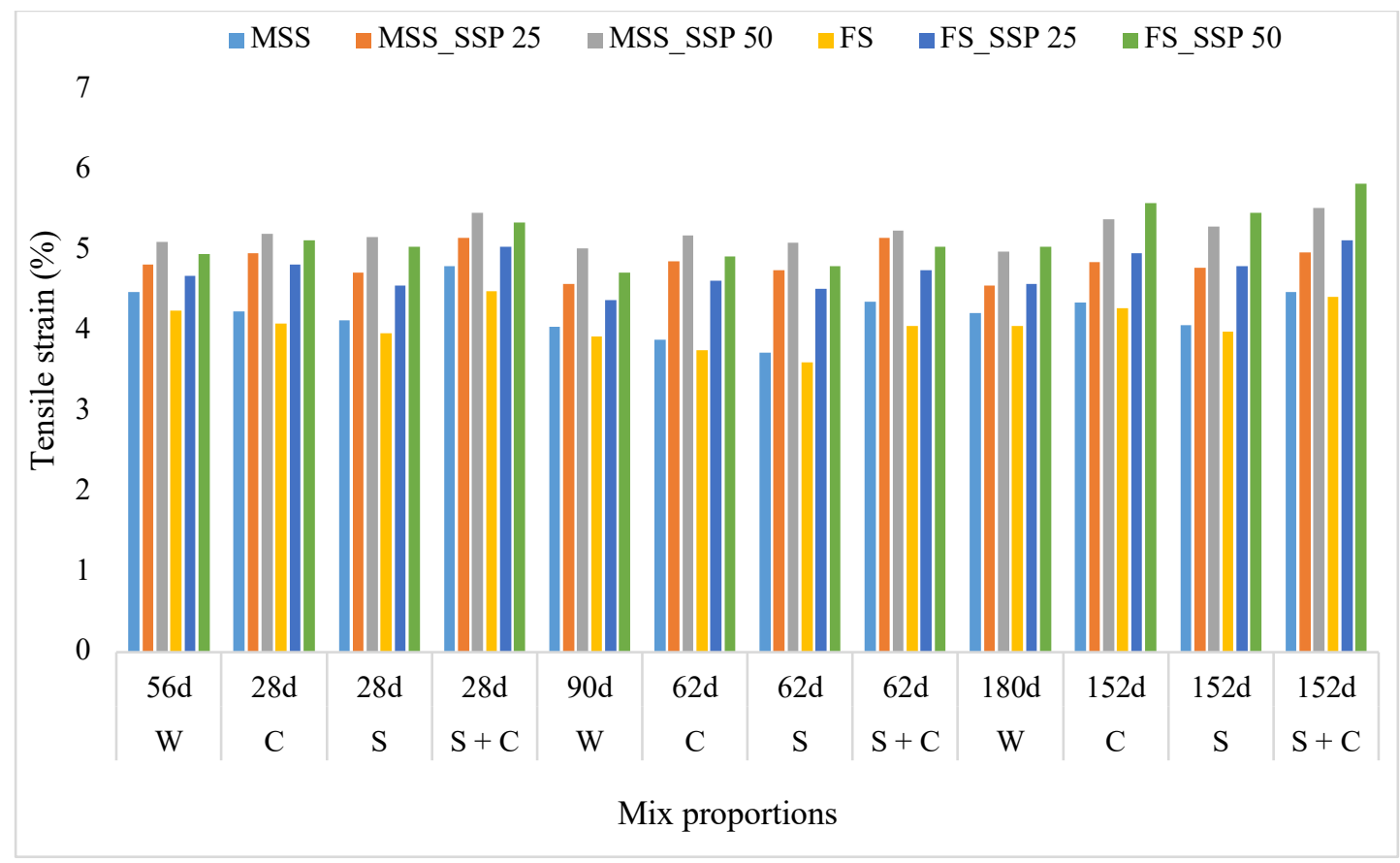

Figure 7. Tensile strain under different environmental conditions at various ages.

\section{CONCLUSION}

This paper experimentally describes the durability performance of various ECC mixes containing SSP. The influence of $25 \%$ and $50 \%$ SSP as subrogation of micro silica sand and fine sand was investigated through CS, TS, ER, and tensile strain characteristics under chloride, sulphate, and combined chloride-sulphate environment. The specific conclusions of this comprehensive appraisal are summarized below. 
- $\quad$ CS, TS, ER, and tensile strain of fully MSS and FS blended mixes decreased after 28 days and 62 days of exposure under various aggressive environments. Pozzolanic reactions of GGBFS in long term diffused the chemical ions after 152 days of exposure and enhanced the performance of fully MSS and FS blended mixes under various aggressive environments.

- The ER of fully MSS blended mix was higher than fully FS blended mix under laboratory and aggressive environment conditions. ER of MSS blended mix was higher due to less voids present with micro size of silica sand than fine sand.

- $\quad$ Utilization of SSP along with both types (MSS \& FS) of sands filled the micro voids of cement matrix and improved the compressive, tensile, and electrical performance of the mixes under water curing as well as under chemical exposure.

- $\quad$ The ER of fully sand (MSS \& FS) containing mixes decreased under aggressive environments. ER of SSP containing mixes was not affected under chloride, sulphate, and combined chloride-sulphate solutions. The ER of various mixes revealed that corrosion chances are negligible in ECC.

- Performance of various mixes revealed that aggressive environments affect the fully FS containing mix more than others due to higher particles size of FS, which makes the porous structure more than MSS and SSP.

- Results from various chemical immersions revealed that sulphate attack is more serious than chloride attack; in combined attack the presence of chloride mitigates the sulphate ions, which is responsible for enhancement under combined chemicals exposure.

- $\quad$ Micro size particles of SSP, when mixed with water in cement matrix, act as a gel and fill the micro voids present on the surface of hydrophobic nature of PVA fiber, which makes the cement matrix structure denser and protects the fiber surface from various aggressive substances, thus responsible for the enhancement in various mechanical properties (CS, TS, ER, and tensile strain) under different chemical exposures. The performance of SSP blended mixes as partial subrogation of each type sand remains durable after 28 days, 62 days, and 152 days of exposure.

Finally, the experimental results from this research demonstrated that SSP containing ECC remains durable under different aggressive environments. The use of SSP as sand in various ECC mixes enhanced the mechanical and durability performance of ECC under aggressive ions. The performance of various mixes revealed that SSP containing ECC can be applied in hydraulic structures under different environment loadings. The present investigation recommends that the SSP can be used up to 50\% subrogation along with MSS and FS. Use of SSP in ECC mix solve the problem of utilization of stone waste and saves the natural resources up to some limit, which gives promising effect on eco-friendly nature of environment.

\section{ACKNOWLEDGEMENT}

The authors feel obliged to the University Grants Commission, New Delhi, for the financial assistance for research work.

\section{REFERENCES}

ACI 224R-01, 2001. Control of cracking in concrete structures.

ACI 222R-01, 2010. Protection of metals in concrete against corrosion.

Al- Amoudi, O.S.B. 2002. Attack on plain and blended cement exposed to aggressivesulphate environments. Cement and Concrete composites 24: 305-316. 
Al-Amoudi, O.S.B. 1998. Sulphate attack and reinforcement corrosion in plain and blendedcements exposed to sulphate environments. Buildingand Environment 33: 53-61.

Al-Dulaijan, S.U., Maslehuddin, M., Al-Zahrani, M.M., Sharif, A.M., Shameem, M.\&

ASTM C1012/C1012M-12. 2012. Standard test method for length change of hydraulic cement mortars exposed to a sulphate solution. ASTM International, West Conshohocken, U.S.A

Anandan, S.K., Islam, S., Khan, R.A. 2019. Effect of steel fibre profile on the fracture characteristics of steel fibre reinforced concrete beams. Journal of Engineering Research 7: 105-124.

Broomfield, J.P. 2007. Corrosion of steel in concrete, $2^{\text {nd }}$ edition, Taylor and Francis, New York.

BS-EN-12390-3, 2009. Testing hardened concrete, Compressive strength of test specimens.British Standard Institution.

Farooqi, M.U. \& Ali, M. 2018. Contribution of plant fibers in improving the behavior andcapacity of reinforced concrete for structural applications. Construction and Building Materials 182: 94-107.

Hussain, S.E. 1994. Corrosion resistance performance of fly ash blended cement concrete. ACI Materials Journal 91: 264-272.

IS 516-1959, 2006. Methods of tests for strength of concrete (18th ed.). Bureau of Indian Standards, New Delhi.

Ibrahim, M. 2003. Sulphate resistance of plain and blended cements exposed to varying concentrations of sodium sulphate. Cement and Concrete composites 25: 429-437.

Lakhani, R., Sharma, R.K.\&Tomar, P. 2014. Utilization of stone waste in the development of value added products: A state of Art Review. Journal of engineering science and Technology Review 7: 180-187.

Lepech, M.\&Li, V.C. 2006.Long term durability performance of engineered cementitious composites. Journal of Restoration of Buildings and Monuments 12: 119-132.

Li, G., Song, A.Z.Z., Liu, S.\&Zhang, J. 2018. Ground granulated blast furnace slag effect on the durability ternary cementitious system exposed to combined attack of chloride and sulphate. Construction and Building Materials 158: 640-648.

Li, M.\& Li, V.C. 2011. Cracking and healing of engineered cementitious composites under chloride environment. ACI Materials Journal108: 333-340.

Li, V.C. 1998. Engineered Cementitious Composites - Tailored Composites through Micromechanical Modeling. Fiber Reinforced Concrete: Present and the Future edited by N. Banthia, A. Bentur, A. and A. Mufti. Canadian Society for Civil Engineering, Montreal, Pp.64-97.

Li,V.C.\& KandaT. 1998.Engineeredcementitiouscompositesforstructuralapplications. Journal of Materials in Civil Engineering 10: 66-69.

Liu, H., Zhang, Q., Gu, C., Su, H.\&Li, V.C. 2017 . Self-healing and microcracks in engineered cementitious composites under sulphate and chloride environment. Construction and Building Materials 153: 948-956.

Liu, H., Zhang, Q., Li, V.C, Su, H.\&Gu, C. 2017 ${ }^{\text {b }}$. Durability study on engineered cementitious composites (ECC) under sulphate and chloride environment. Construction and Building Materials 133: 171-181.

Madani, H., Bagheri, A., Parhizkar, T., Raisghasemi, A. 2014.Chloride penetration and electrical resistivity of concretes containing nanosilica hydrosols with different specific surface areas. Cement and Concrete Composites 53: 18-24.

Medeiros-Junior, R.A.\& Lima, M.G. 2016. Electrical resistivity of unsaturated concreteusing different types of cement. Construction and Building Materials 107: 11-16.

Neville, A.M. 2012. Properties of Concrete, fifth ed., Trans-Atlantic Publications, Inc., Harlow, England; New York. 
Ozbay, E., Karahan, O., Lachemi, M., Hossain, K.M.A.\&Atis, C.D. 2013. Dual effectiveness of freezingthawing and sulphate attack on high-volume slag-incorporated ECC. Composites: Part B 45: 1384-1390.

Ramezanianpour, A.A., Pilvar, A., Mahdikhani, M.\&Moodi, F. 2011. Practical evaluation of relationship between concrete resistivity, water penetration, rapid chloride penetration and compressive strength. Construction and Building Materials 25: 2472-2479.

Sahmaran, M. \& Li V.C. 2008. Durability of mechanically loaded engineered cementitious composites under highly alkaline environments. Cement and Concrete Composite 30: 72-81.

Sahmaran, M. \& Li, V.C. 2009. Durability properties of micro-cracked ECC containing high volumes fly ash. Cement and Concrete Research 39: 1033-1043.

Sahmaran, M., Li, M.\&Li, V.C. 2007. Transport Properties of Engineered Cementitious Composites Under Chloride Exposure. ACI Materials Journal 104: 604-611.

Salami, B.A., Johari, M.A.M., Ahmad, Z.A.\&Maslehuddin, M. 2017.Durability performance of Palm Oil Fuel Ash-based Engineered Alkaline activated Cementitious Composite (POFA-EACC) mortar in sulphate environment. Construction and Building Materials 131: 229-244.

Santhanam, M., Cohen, M.\&Olek, J. 2006. Differentiating seawater and groundwater sulphate attack in portland cement mortars. Cement and Concrete Research 36: 2132-2137.

Sibbick, T., Fenn, D.\&Crammond, N. 2003. The occurrence of thaumasite as a product of seawater attack. Cement and Concrete Composites 25: 1059-1066.

Singh, M., Saini, B. \&Chalak, H.D. 2019a . Performance and composition analysis of engineered cementitious composite (ECC) - A review. Journal of Building Engineering 26: 100851. https://doi.org/10.1016/j.jobe.2019.100851.

Singh, M., Saini, B. \&Chalak, H.D. 2019 . Properties of Engineered Cementitious Composites: A Review. Proceedings of the 1st International Conference on Sustainable Waste Management through Design, pp. 473-483. https://link.springer.com/chapter/10.1007/978-3-030-02707-0_54

Singh, M., Saini, B.\&Chalak, H.D. 2019 ${ }^{\text {c }}$ Appraisal of Hybrid Fiber Reinforced Engineered Cementitious Composite. Proceedings of the 4th International Conference on Civil, Structural and Transportation Engineering (ICCSTE'19) Ottawa, Canada. DOI: 10.11159/iccste19.192

Skalny, J., Marchand, J.\&Odler, I. 2002. Sulphate attack on concrete. Modern Concrete Technology. Pp. 217232, CRC Press

Taylor, H.F.W., Famy, C.\&Scrivener, K.L. 2001. Delayed ettringite formation. Cement and Concrete Research. 31: 683-693.

Teng, S., Afroughsabet, V.\&Ostertag, C.P. 2018. Flexural behavior and durability properties of highperformance hybrid-fiber-reinforced concrete. Construction and Building Materials 182: 504-515.

Ulubeyli, G.C., Bilir, T.\&Artir, R. 2016. Durability properties of concrete produced by marble waste as aggregate or mineral additives. Procedia Engineering 161: 543 - 548.

Zhou, J., Qian, S., Beltran, M.G.S., Ye, G., Breugel, K.V.\&Li, V.C. 2010. Development of engineered cementitious composite with limestone powder and blast furnace slag. Materials and Structures 43: 803814.

Zia, A.\& Ali, M. 2017.Behavior of fiber reinforced concrete for controlling the rate of cracking in canal-lining. Construction and Building Materials 155: 726-739.

Zivica, V.\& Szabo, V. 1994. The behaviour of cement composite under compression load at sulphate attack. Cement and Concrete Research 24:1475-1484. 